\title{
Morphological Study of Polyimide Mixed Matrix Membranes
}

\author{
O. Bakhtiari ${ }^{1}$, T. Khosravi ${ }^{2}$, S. Mosleh ${ }^{3} \&$ T. Mohammadi ${ }^{4}$ \\ ${ }^{1.4}$ Research Center for Membrane Separation Processes, Department of Chemical Engineering, Iran University of \\ Science and Technology (IUST), Narmak, Tehran, Iran
}

\begin{abstract}
Polyimide mixed matrix membranes (MMMs) were synthesized by incorporating different fillers of zeolite $4 \mathrm{~A}$, carbon molecular sieve, and homemade carbon nanotubes into Matrimid 5218 and P84 via solution casting method. MMMs were characterized by Scanning Electron Microscopy (SEM), Differential Scanning Calorimeter (DSC) and Thermo Gravimetric Analysis (TGA) . Effects of fillers loading and polymer concentration on MMMs structure and thermal treatment on removing MMMs probable defects were investigated. The experimental results showed that filler particle size, nature and polymer concentration have significant effects on filler distribution inside the polymer matrices. Incorporation of fillers inside the polymers resulted in polymer free volume reduction and polymer chain attachment to and/or entrance into fillers pores and more glassy (brittle) MMMs as can be concluded by DSC and TGA analysis. Thermal treatment was found as an effective method for removing probable defects inside the MMMs.
\end{abstract}

Keywords: Mixed matrix membrane, polyimide, filter size and nature, polymer concentration, thermal treatment, morphology

\section{$1.0 \cdot$ INTRODUCTION}

Membrane based separation processes are fast developing in current existing and for coming industries. Membrane materials need to be modified to fully and economically exploit available opportunities. High stability, permeation flux and selectivity at low production cost are always the most important criteria when developing a membrane for a specific application

\footnotetext{
* Corresponding to: T. Mohammadi (email: torajmohanmadi@iust.ac.ir)
}

[1]. Many efforts are being carried out to modify current membrane materials. Ion exchange is a method for improving separation performance of zeolitic membranes[2-3]. Others are Crosslinking, grafting and blending which were also applied for polymeric membranes [4-8]. Due to the membrane material unique characteristics, researchers are seeking for new approach to employ desired properties of fine inorganic particles incorporated in polymers to form a so called "Mixed Matrix Membranes (MMMs)." Therefore, the new generation of membrane researchers are trying 
to employ desired properties of fine particles and polymers while omitting their undesired properties [9-11].

Proper polymer and filler selection, preparation and post-treatment procedure are of the most important key features in successful MMMs preparation [9, 11]. Filler size, content and polymer concentration are among the affecting parameters on filler distribution inside polymer matrix and MMMs separation performance [11-13]. Many researches have been focused on rubbery polymers with high affinity to fillers and there are approximately good connections between polymer and filler phases $[9,14]$. Glassy polymers exhibit higher separation performance with regard to rubbery polymers and at the same time have higher rigidity in nature and they are hard to incorporate with inorganic fillers $[11,14]$. Void formation around the incorporated fillers, fillers pores blockage by polymers and chain rigidification are undesired phenomena that can potentially occur in MMMs preparation especially for glassy polymers and these result in MMMs morphology to be apart from ideal morphology [9-11, 15]. Different morphologies may be observed in MMMs as shown schematically in Figure 1 [9].
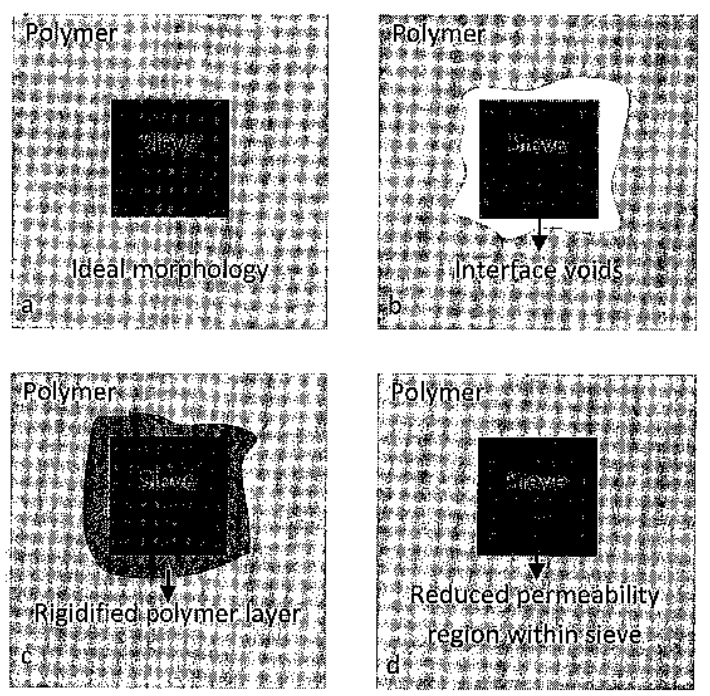

Figure 1 Ideal and different non-ideal cases may be encountered in MMMs preparation [9]
Similar to that mentioned in literature by Jiang et al. [12], a synthesis procedure was employed to study the effects of synthesis parameters on MMMs structure [9, 11-12]. Objective of this study was to develop defect-free MMMs using glassy polyimides of Matrimid 5218 and P84 and zeolite 4A, carbon molecular sieve and homemade carbon nanotube (CNT) as fillers. Polyimides have high glass transition temperatures, $T_{g}$, and exhibit excellent thermal stability. Glassy polymers of Matrimid 5218 and P84 have glass transition temperatures of $\sim 300$ and $315^{\circ} \mathrm{C}$, respectively and are reasonably chemically stable in most organic solvents and weak acids [11].

\subsection{EXPERIMENTAL}

\subsection{Materials and Equipments}

Matrimid 5218 was purchased from Huntsman Chemical Company, USA. P84, zeolite 4A and carbon molecular sieve (CMS) were dedicated by HPPolymerCo, Iran Research Institute of Petroleum Industries and Activated Carbon Business Divisions, Japan EnviroChemical, respectively. Normal Methylpyrrolidone (NMP, $\geq$ $99.5 \%$ ) was purchased from Merck Chemicals Co. as solvent and used as received. Some glass plates and holder meshes were fabricated in order to prepare MMMs. A vacuum oven (Wisd, WiseVen), an oven (Memmert), some stirrers (FALC, F20, Italy) and a digital microbalance (Percisa, 310 M) were also used. A programmable oven was also used to thermally treat the MMMs.

\subsection{Preparation of MMMs}

Polymer powders and filler particles were activated over-night at $120^{\circ} \mathrm{C}$ under vacuum to remove any adsorbed impurities. After activation, the filler was suspended in the solvent and stirred for about $24 \mathrm{~h}$ at room temperature and then the polymer was added and stirred at room temperature for the next $24 \mathrm{~h}$. The as-prepared solution was cast onto a glass plate after degassing in vacuum for $4 \mathrm{~h}$ followed by solvent evaporation at $170^{\circ} \mathrm{C}$ for about $2 \mathrm{~h}$. The nascent membranes 


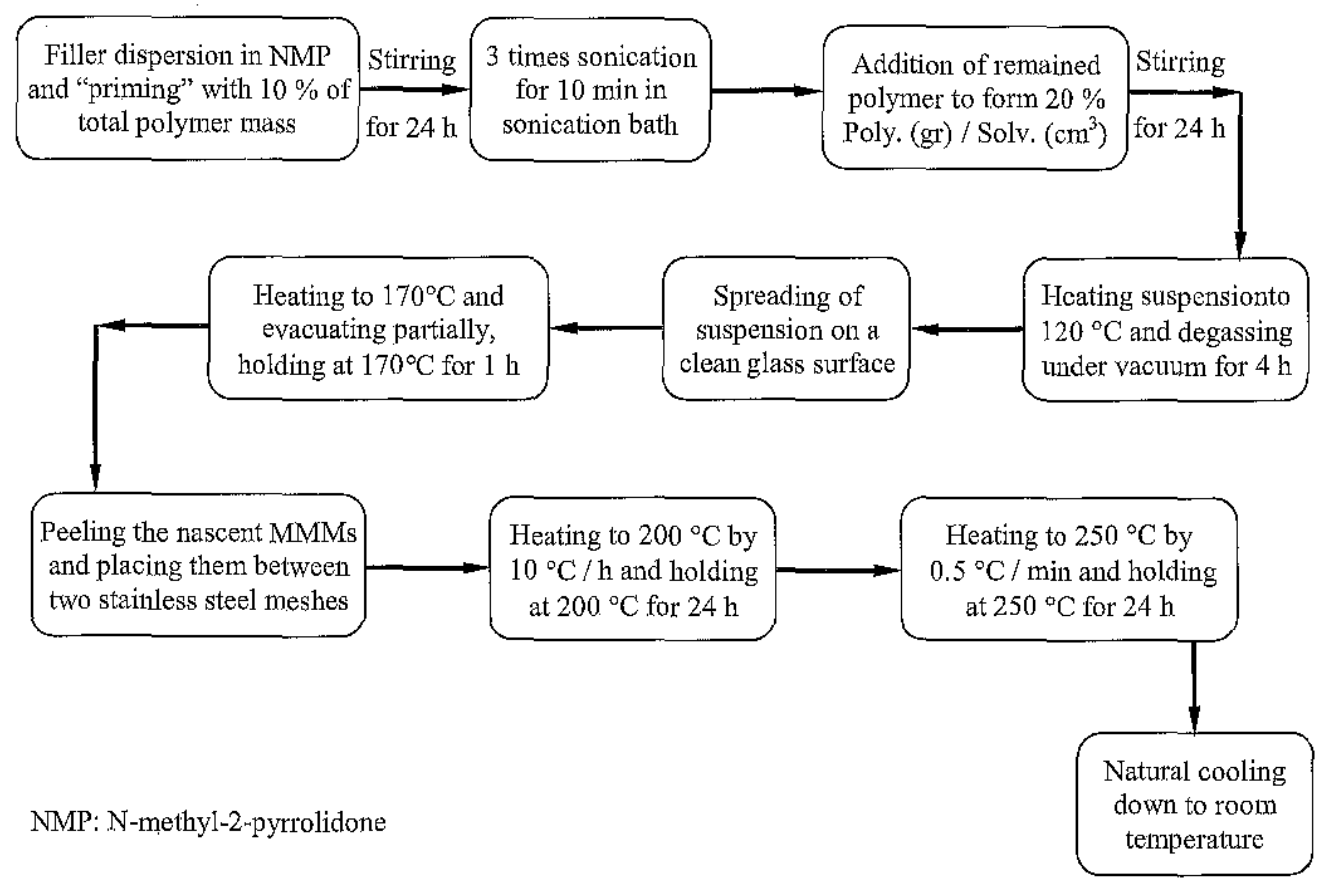

Figure 2 Modified MMMs preparation procedure based on L. Y. Jiang et al. [12]

were then heated inside the oven for $2 \mathrm{~h}$, the membranes were peeled off from the glass plates, and put in between two wired stainless steel meshes individually to balance heat transfer from top and bottom of each membrane. As a result, the solvent at the bottom side of the membrane could be removed more efficiently, and the membrane could be more homogeneous [12]. Later, the membranes were hold at about $200^{\circ} \mathrm{C}$ overnight to fully remove the solvent. The membranes were further annealed at a rate of $0.5^{\circ} \mathrm{C} / \mathrm{min}$ to $250^{\circ} \mathrm{C}$ and remained for $12 \mathrm{~h}$. This step could also help removing the residual solvent. The MMMs were finally allowed to be cooled naturally down to room temperature. Thickness of the membranes was in the range of 35-60 $\mu \mathrm{m}$ as measured by a Mitutoyo micrometer (accuracy of $1 \mu \mathrm{m}$ ). The process was based on Ying Jiang et al. [12] procedure with a little difference as reported in Figure 2.

\subsection{Membranes Characterization}

Geometrical characteristics and morphology of the MMMs were observed using a VEGAI\TESCAN SEM. The samples were prepared by fracturing in liquid nitrogen then coated with $\mathrm{Au}$. Glass transition temperatures, $T_{g}$, of the neat polymeric membranes and MMMs were measured using a Perkin Elmer-Pyris 6 DSC with heating and cooling rates of $10^{\circ} \mathrm{C} / \mathrm{min}$ under nitrogen environment up to $600^{\circ} \mathrm{C}$. Perkin ElmerPyris diamond TGA was performed in order to evaluate thermal stabilities of the prepared MMMs and the neat polymeric membranes. The samples were heated circularly from 30 to $600^{\circ} \mathrm{C}$ with heating rate of $10^{\circ} \mathrm{C} / \mathrm{min}$ under nitrogen environment. 


\subsection{RESULTS AND DISCUSSION}

\subsection{SEM Studies}

Cross section of the neat Matrimid membrane is shown in Figure 3. Nano-sized $(\sim 10 \mathrm{~nm})$ aerosil silica was dispersed inside P84 (10 wt.\%). Particles were be agglomerated $(\sim 5 \mu \mathrm{m})$ and partially sedimented into the MMM due to the gravitational force (Figure 4, a). As observed, the agglomerated particles tend to move to the lower surface of the MMM (Figure 4, b) and the density of aerosil silica particles is less in the upper surface. Different precaution efforts including sonication before casting to dissociate aggregated particles [16] and using more concentrated suspensions to partially balance gravitational force $[9,12]$, were performed.

Larger 4A zeolite particles (300 - $500 \mathrm{~nm}$ as reported by the dedicator) was incorporated into Matrimid 5218 (10 wt.\%). The particles were aggregated again but there was more uniform filler distribution as observed in Figure 5. Top surface and cross section SEM images show better distribution of zeolite $4 \mathrm{~A}$ than that of silica aerosil. There is greater buoyant force and as a result less sedimentation occurs. Generally, fillers sedimentation in MMMs is inevitable since there are nearly large density difference between inorganic fillers (typically $1.3 \mathrm{gr} / \mathrm{cm}^{3}$ ) and solvents (typically $0.9 \mathrm{gr} / \mathrm{cm}^{3}$ ). Larger fillers (micro-sized) results in slightly better distribution as shown in Figure 6 for CMS - Matrimid 5218

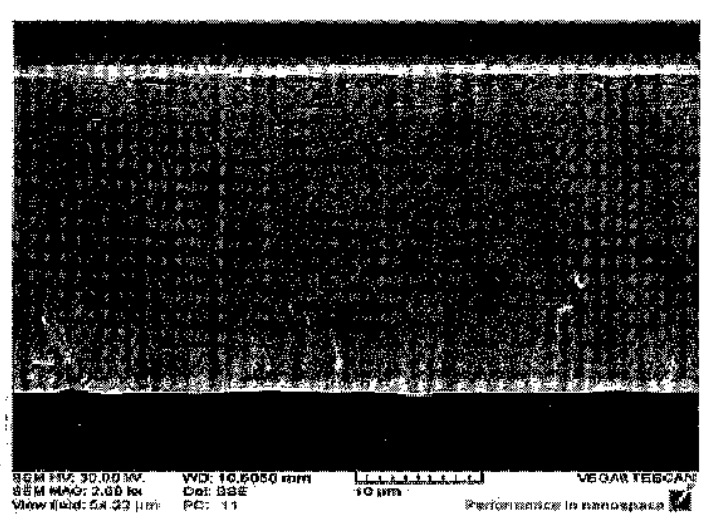

Figure 3 Cross-sectional SEM image of the neat Matrimid 5218 membrane

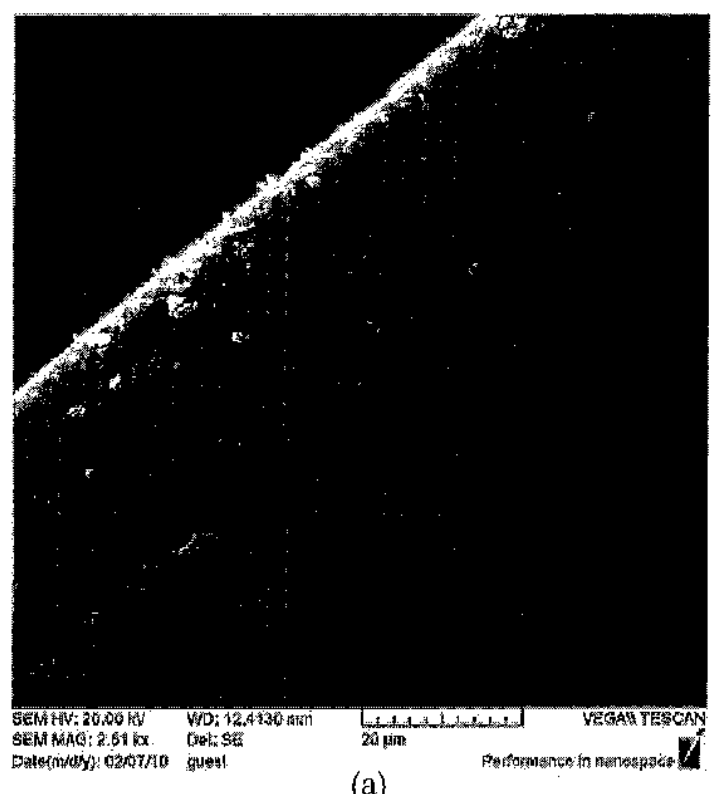

papt

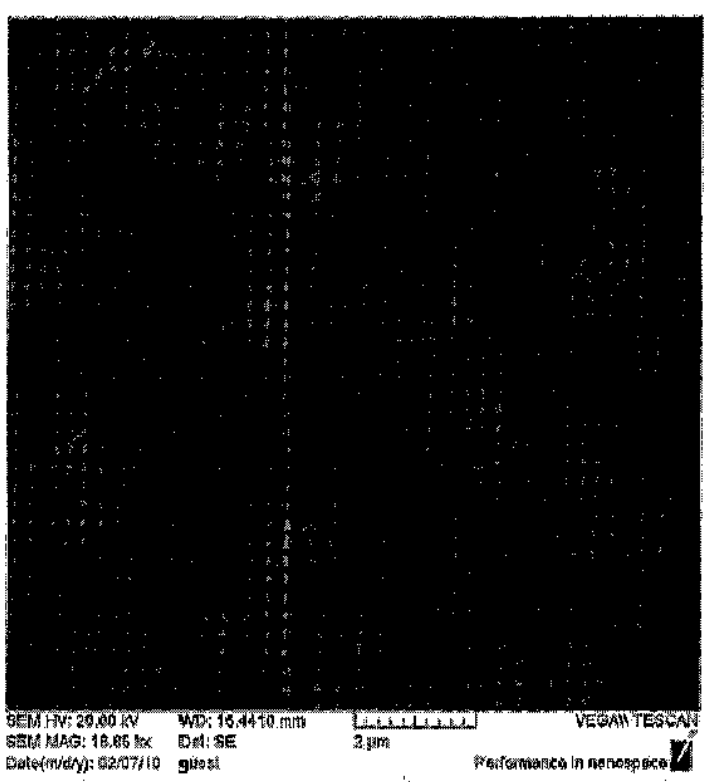

(b)

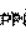

Figure 4 SEM image of $10 \mathrm{wt} . \%$ aerosil silica Matrimid 5218 (10 wt.\%) MMM, average thickness of $35 \mu \mathrm{m}$, (a) cross section, (b)lower surface.

(10 wt.\%). Since CMS has lower density and larger volume, it is affected by greater buoyant force and more uniform filler distribution is obtained. However, in separation point of view, 


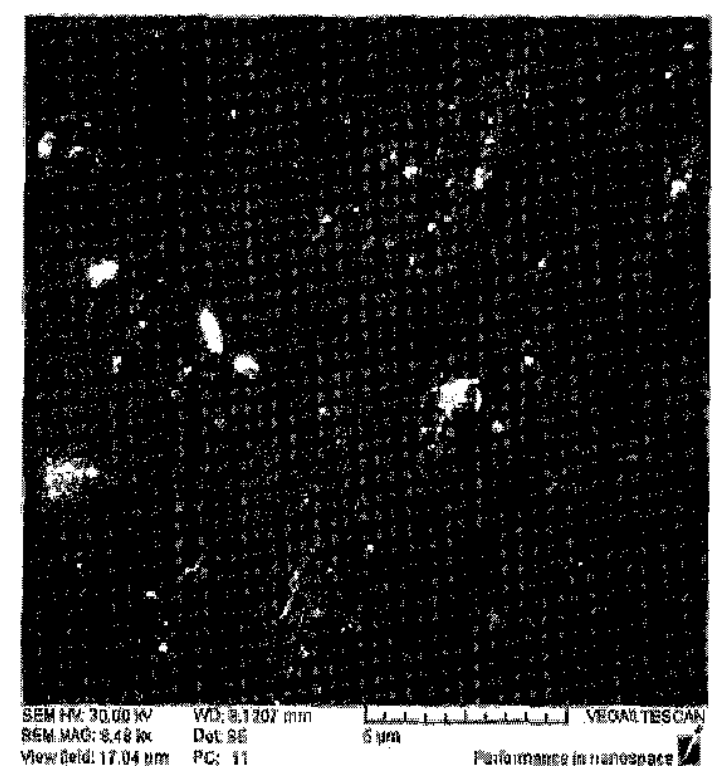

(a)

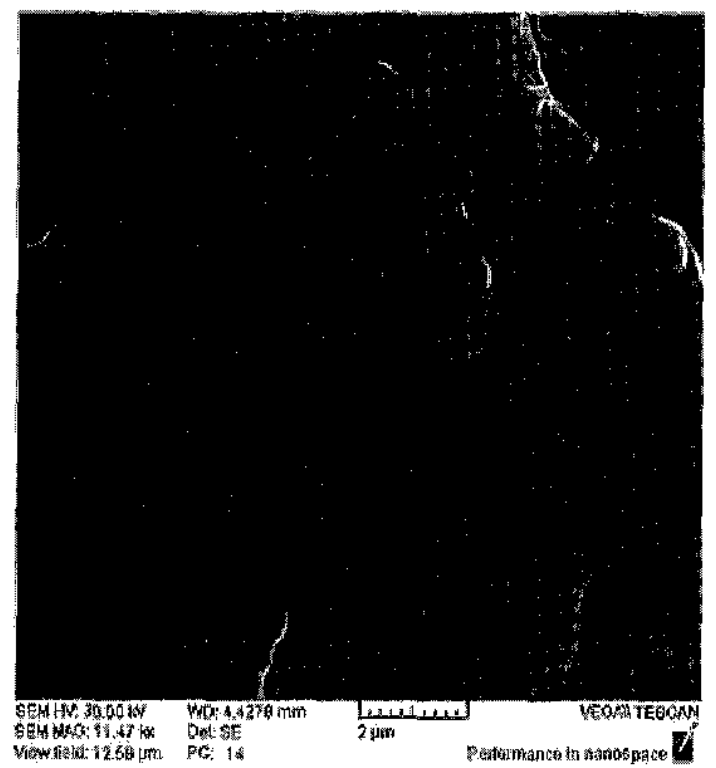

(b)

Figure 5 SEM image of 10 wt. \% zeolite $4 \mathrm{~A}$ Matrimid 5218 (10 wt. \%) MMM, average thickness of $45 \mu \mathrm{m}$, (a) top surface, (b) cross section

incorporation of smaller particles results in better performance $[9,17]$.

As mentioned above, concentration (viscosity) of the casting solution to form MMMs, is one of

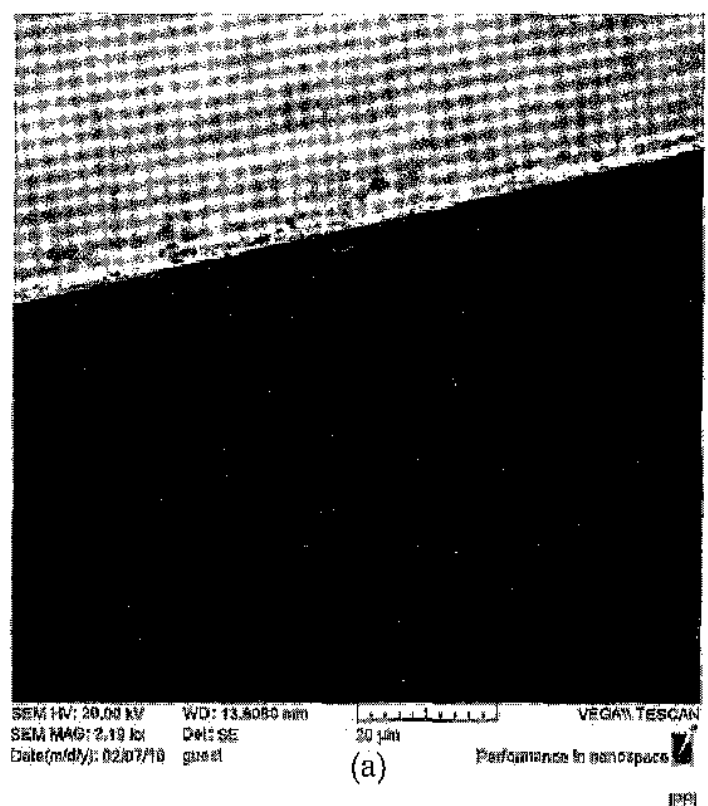

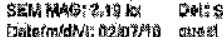

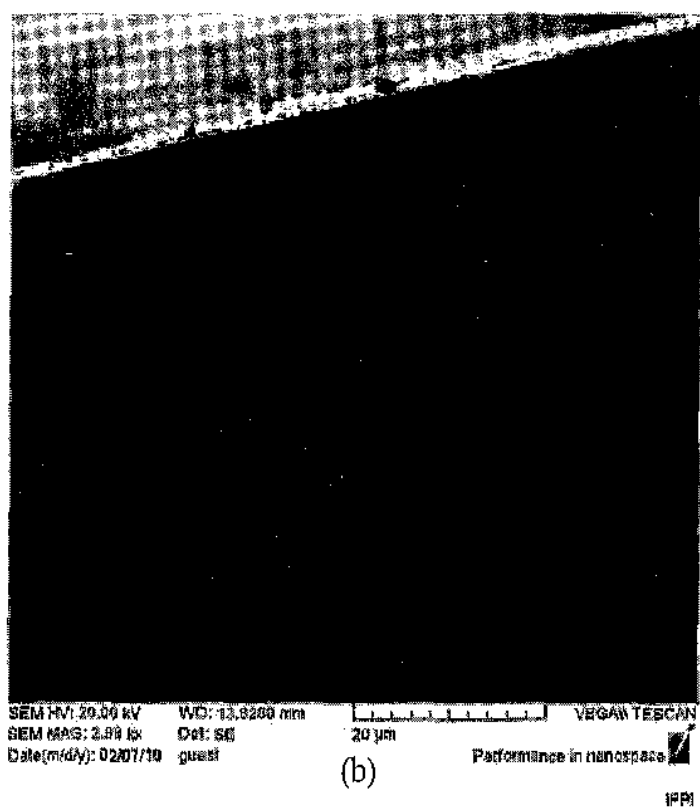

Figure 6 Cross section SEM image of 10 wt.\% CMS - Matrimid 5218 (10 wt.\%) MMM, average thickness of $45 \mu \mathrm{m}$

the main affecting parameters on the filler distribution within the MMMs structure $[9,12]$. More concentrated (viscose) solutions were employed to prepare MMMs and the results 


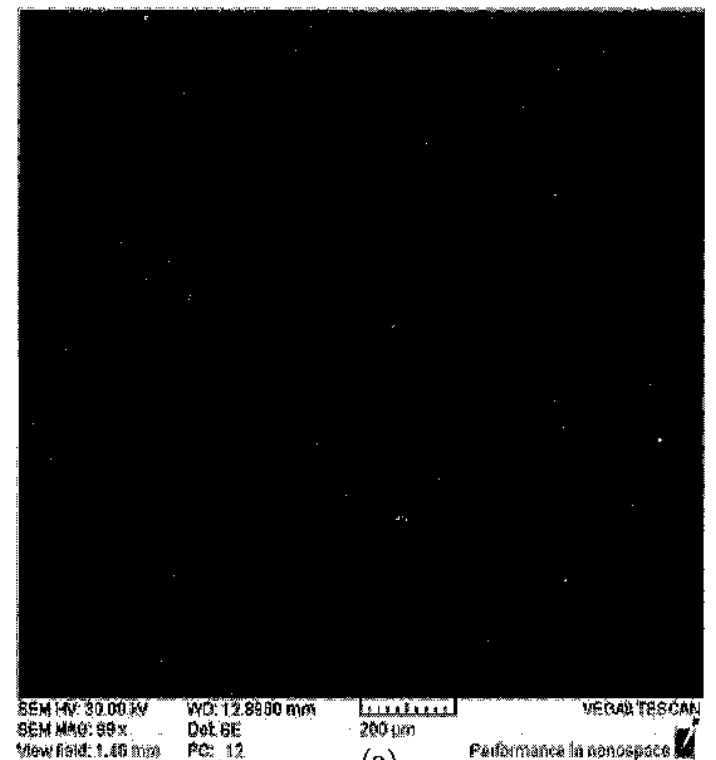

(a)
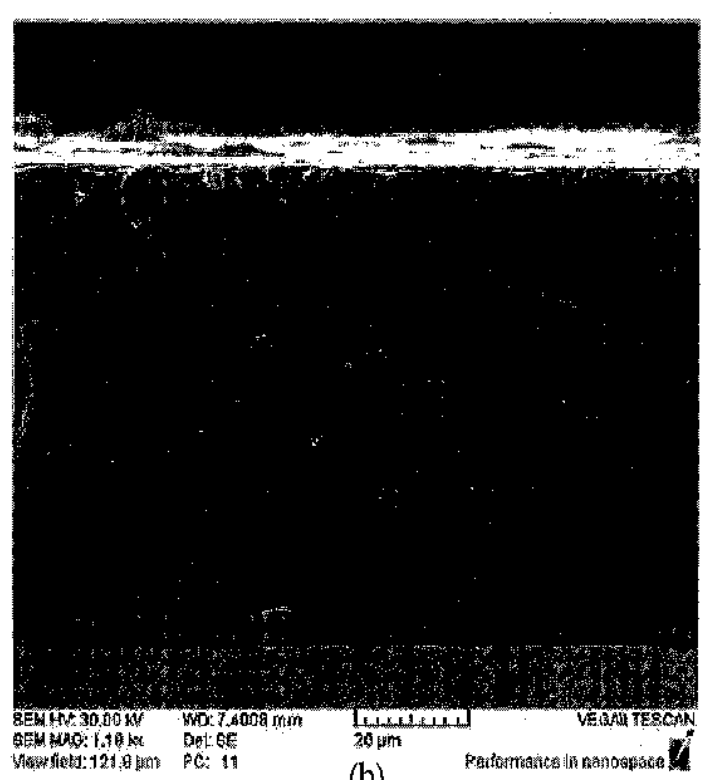

Figure 7 SEM image of $5 \mathrm{wt} . \%$ zeolite ZSM-5 Matrimid 5218 (15 wt.\%) MMM, average thickness of $55 \mu \mathrm{m}$, (a) top surface, (b) cross section

showed more uniform distribution of the filler, as indicated in Figure 7 ( $a$ and $b$ ) for zeolite ZSM-5 (5wt.\%)-Matrimid 5218 (15 wt.\%) MMM. Nearly a uniform filler distribution is observed in cross section, indicating the effectiveness of solution concentration (viscosity) on the filler distribution.

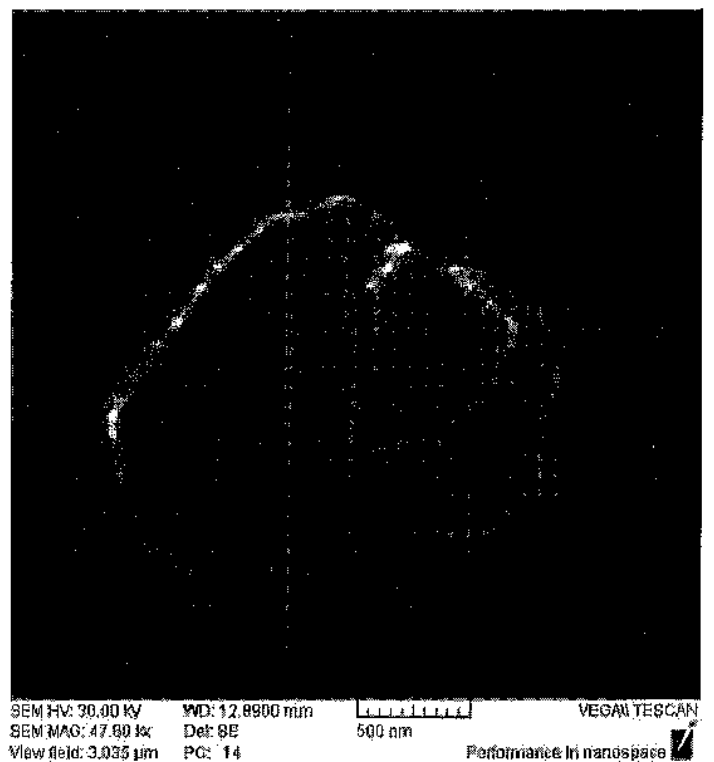

Figure 8 Top SEM image of $5 \mathrm{wt}$ \% zeolite ZSM5 - Matrimid 5218 (15 wt.\%) MMM, average thickness of $55 \mu \mathrm{m}$

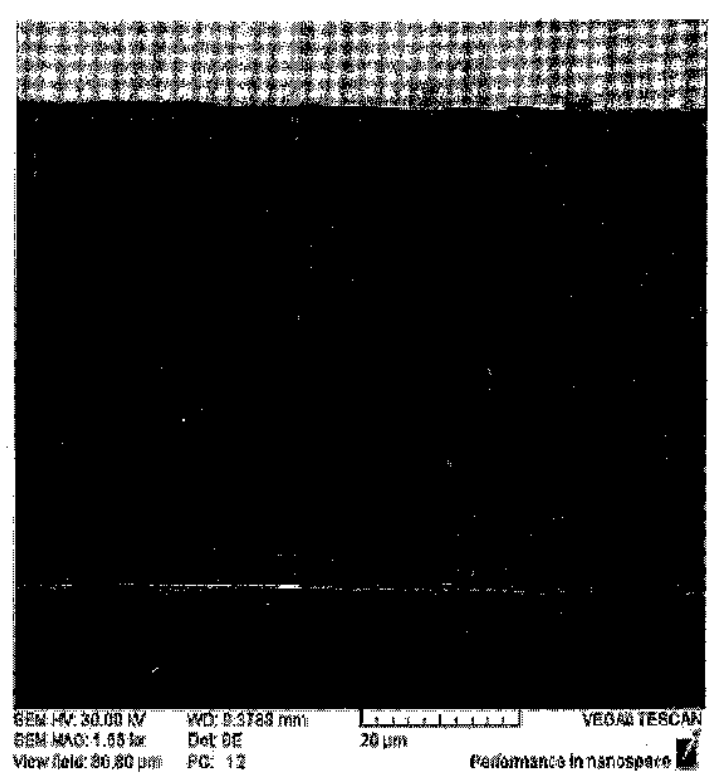

Figure 9 Cross section SEM image of $5 \mathrm{wt} . \%$ CMS - P84 (15 wt.\%) MMM, average thickness of $50 \mu \mathrm{m}$

Better connection between filler particles and polymer is also observed in more concentrated (viscose) solutions as reported in Figure 8 for the ZSM-5 (5 wt.\%) -Matrimid 5218 (15 wt.\%) MMM. 
The same behavior is observed in the case of micro-sized CMS dispersed in a more viscose solution (Figure 9).

\subsection{DSC and TGA Studies on Prepared Membranes}

As inorganic filler is incorporated inside a polymer matrix, the end chains of polymer molecules may be attached to the inorganic filler particles surface by chemical (or hydrogen) bonding, or entered to the pores of filler particles. In both cases, the polymer chains in a certain region around the filler particles are rigidified and this results in restriction of polymer chains movement (Figure 1,c and d) [9, 18-19]. Zhang et al. employ edcalcined and uncalcined ZSM-5 and observed that polymer chains entrance doesn't occur in the case of uncalcined ZSM-5 which is plugged by a template. They concluded that the presence of mesopores is a key parameter to achieve a good contact [19]. Although the good contact may be observed in such cases, chaotic polymer chains entrance into filler particles may result in smaller aperture for penetrants and abortiveness of fillers [20].

DSC analysis of granular Matrimid 5218 showed $T_{\mathrm{g}}$ of $297^{\circ} \mathrm{C}$ as indicated in Figure 11. The neat Matrimid 5218 membrane was also investigated using cyclical DSC and its $T_{g}$ was found to be 291 ÚC (Figure 12). The deviation can be related to the different analytical equipments. The prepared MMMs were also investigated using DSC analysis. The results showed that incorporation of fillers inside polymer matrices increases $T_{g}$ of the MMMs compared with these of the neat polymeric membranes due to the filler polymer chains interactions. The interactions can be in form of physical or chemical bonding to the filler surface or polymer chain entrance into the filler pores. $T_{g}$ values of the MMMs are reported in Table 1. By adding more filler, free volume of polymer reduces since it is occupied by the filler and some rigidified regions appeared in the neighborhood of filler particles $[12,19]$. In other words, the incorporated filler particles restrict movement and alignment of the polymer chains around the filler

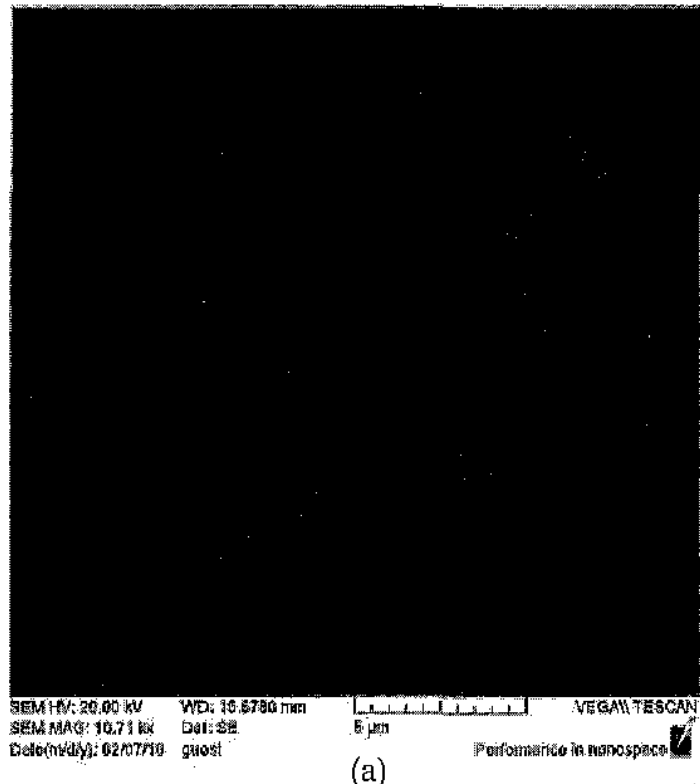

(a) เ中⿰习习

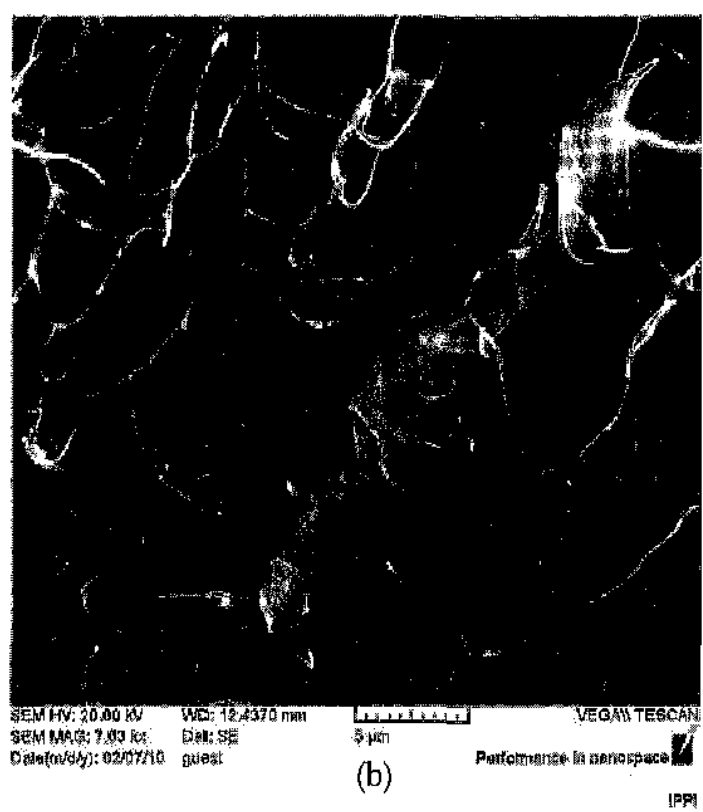

Figure 10 Cross section SEM image of $5 \mathrm{wt} . \%$ CMS - P84.(15 wt.\%) MMM, average thickness of $50 \mu \mathrm{m}$

and this causes $T_{g}$ value to increase [1]. The results showed that incorporation of zeolite $4 \mathrm{~A}$ results in more brittle MMMs and this can be attributed to its tough nature. As zeolite 4A content increases, glassier MMM with higher $T_{g}$ 


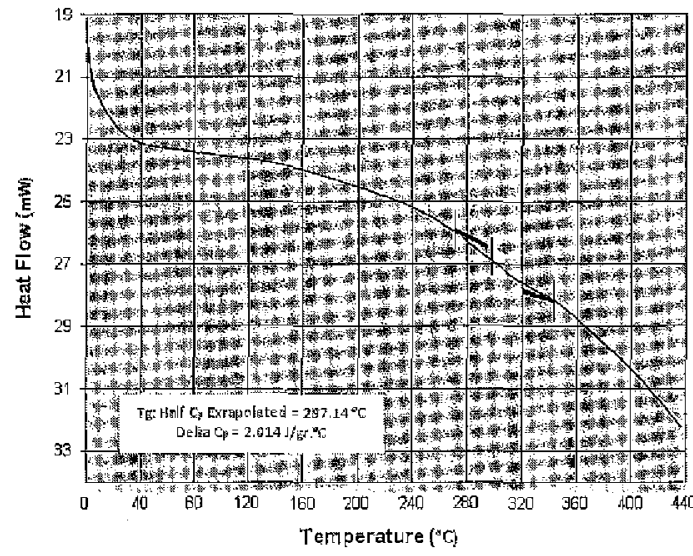

Figure 11 DSC analysis of the granular Matrimid. 5218

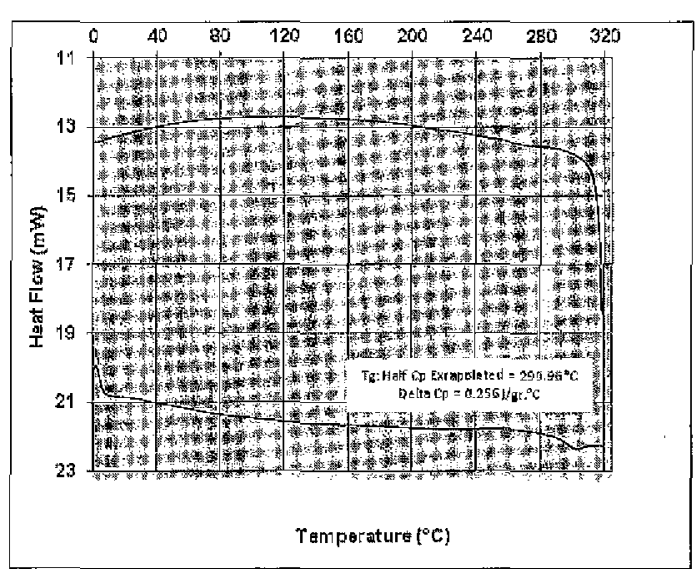

Figure 12 DSC analysis of the neat Matrimid 5218 membrane

is obtained due to the more filler-polymer chains interactions. CMS is softer than zeolite $4 \mathrm{~A}$ and as a result MMMs containing CMS are more flexible and their $T_{g}$ values are lower.

The prepared membranes were also studied using TGA for their thermal stabilities. The neat Matrimid $5218(10 \mathrm{wt} \%$ ) membrane and zeolite 4A (5 and 15 wt.\%) and CMS (15 wt.\%) Matrimid 5218 (10 wt.\%) MMMs were studied. The results (Figure 13) showed that after $500^{\circ} \mathrm{C}$, thermal stabilities of the MMMs are higher than that of the neat membrane (weight losses of the
Table 1 DSC analysis of the granular Matrimid 5218

\begin{tabular}{lll}
\hline $\begin{array}{l}\text { Polymer (wt.\% } \\
\text { in NMP }\end{array}$ & Filler (wt.\%) & $\mathrm{T}_{\mathrm{g}}(\mathrm{C})$ \\
\hline $\begin{array}{l}\text { Matrimid5218 } \\
(10)\end{array}$ & zeolite 4A (5) & 298 \\
$\begin{array}{l}\text { Matrimid5218 } \\
\text { (10) }\end{array}$ & zeolite 4A (15) & 306 \\
$\begin{array}{l}\text { Matrimid5218 } \\
\text { (10) }\end{array}$ & CMS (10) & 296 \\
\hline
\end{tabular}

neat Matrimid 5218 (10 wt.\%) membrane and zeolite 4A (15 wt.\%) - and CMS (15 wt.\%)Matrimid 5218 (10 wt.\%) MMMs were recorded as $34.51,32.23$ and $27.86 \%$, respectively). Higher thermal stabilities of the CMS-Matrimid 5218 MMM may be due to the large pore aperture of CMS ( $\sim 50 \AA$, as reported by the manufacturer) and the more polymer chains entrance to CMS pores. Also, there are larger rigidified regions around and inside the fillers [18], while CMS nature is softer than zeolite $4 \mathrm{~A}$. The analysis showed connections formed between the polymers and the fillers, while rigid glassy polymers were employed. As observed, as filler content in MMMs increases, their thermal stabilities increase as indicated in Figure 14 for 5 and $15 \mathrm{wt} . \%$ of zeolite $4 \mathrm{~A}$ in Matrimid $5218 \mathrm{MMMs}$. Incorporation of more fillers results in higher filler-polymer chains interactions and more rigidified regions in the MMMs.

\subsection{Effects of Annealing}

Non-ideal morphologies as explained above are inevitable in most cases. However, some precautions and/or treatment processes should be considered in order to prevent formation of these defects and/or remove them. The main defect in MMMs structure, especially for those of glassy polyimides, is detachment of the polymer chains from the filler surface and void formation around 


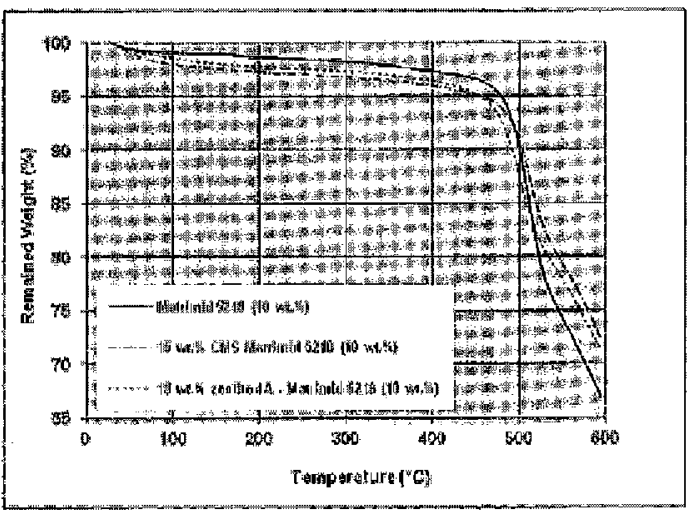

Figure 13 TGA analysis of the prepared neat and MM Matrimid 5218 membranes

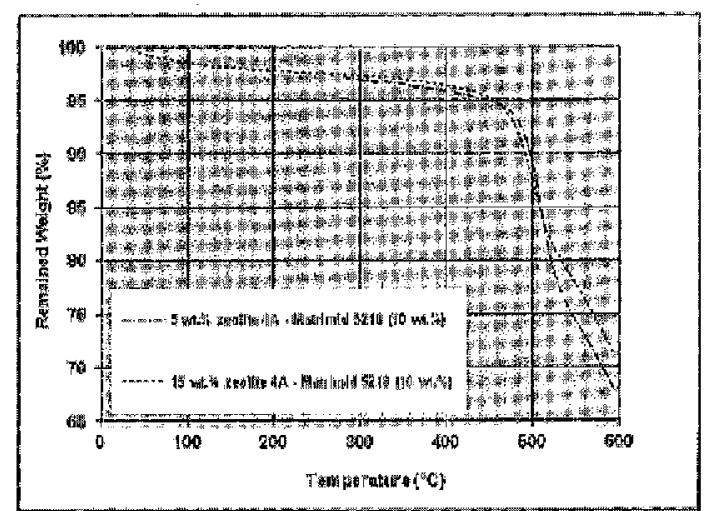

Figure 14 TGA analysis of the prepared of zeolite $4 \mathrm{~A}$ ( 5 and $15 \mathrm{wt} . \%$ ) - Matrimid 5218 (10wt.\%) MMMs

the filler particles. One of the most effective posttreatment processes that can remove the voids around the filler particles is to perform thermal treatment on the prepared MMMs at temperatures around their $T_{g}$ values. This enhances polymer chains mobility and allows the remained stresses or drying stresses to be annealed and an integrated MMM to be formed. In the current study, some homemade CNT [21] (10 wt.\%) - P84 (10 wt.\%) MMMs were prepared to investigate thermal treatment effectiveness on removing the probable defects. Investigation of the MMMs before and after thermal treatment are based on Jiang et al. [12] procedure. The results from SEM images (Figure 15), showed that thermal treatment could effectively repair the probable defects which were the results of shrinkage or residual drying stresses.

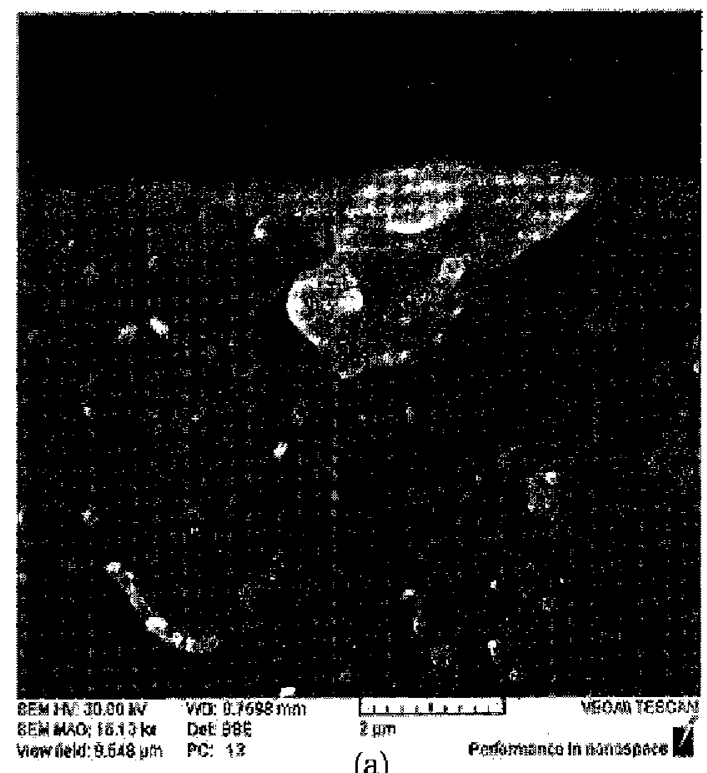

(a)

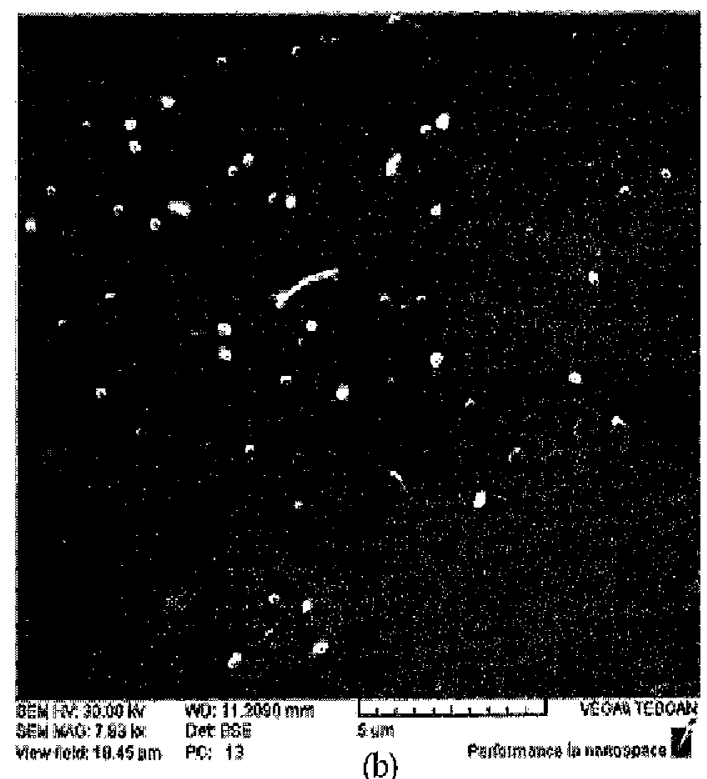

Figure 15 Cross sectionSEM image of $10 \mathrm{wt} \%$ CNT - P84 (10 wt.\%) MMM, average thickness of $55 \mathrm{im}$, (a) as dried at 80 ${ }^{\circ} \mathrm{C}$ and 1 bar, (b) after thermal treatment viathe procedure based on Jiang et al. procedure[12] 


\subsection{CONCLUSION}

In this study, zeolite 4A, CNT and CMS-Matrimid 5218and P84 MMMs were fabricated. Some affective variables were investigated on MMM formationusing SEM, DSC and TGA analysis. Size and density of fillers were found to have strong effects on their distribution within the polymer matrices. Polymer solution concentration (viscosity) was found as another effective variable on fillers distribution within MMMs structure. Incorporation of fillers inside polymers resulted in higher $T_{g}$ and thermal stabilities of MMMs as compared with those of neat polymeric membranes due to polymer chains attachment (and consequently rigidification) and/or chains entrance into filler pores. Nature and content of fillers were also found as the most determining variables. Thermal treatment was found as an effective solution for removing probable defects in MMMs structure. Effects of different parameters on MMMs structure and their separation performance are under investigation.

\section{ACKNOWLEDGEMENT}

The financial support of Iran National Science Foundation (INSF) is warmly appreciated. HPPolymer Co., Japan EnviroChemical, and Iranian Research Institute of Petroleum Industries are appreciated sincerely for dedication of different types of materials.

\section{REFERENCES}

[1] Qiao, X., T.-S. Chung, and R. Rajagopalan. 2006. Zeolite Filled P84 Co-polyimide Membranes for Dehydration of Isopropanol through Pervaporation Process. Chemical Engineering Science. 61: 6816-6825.

[2] Hong, M., et al. 2007. Ion-exchanged SAPO-34 Membranes for Light Gas Separations. Microporous and Mesoporous Materials. 106: 140-146.

[3] Yasuhisa Hasegawa, T. T., Kaori Watanabe,
Byeong-Heon Jeong, Katsuki Kusakab and Shigeharu Morooka. 2002. Separation of $\mathrm{CO}_{2} \cdots \mathrm{CH}_{4}$ and $\mathrm{CO}_{2}-\mathrm{N}_{2}$ Systems using Ionexchanged FAU-type Zeolite Membranes with Different Si/Al Ratios. Korean Journal of Chemical Engineerig. 19: 309-313.

[4] Li, X.-G., Kresse, I., Springer, J., Nissen, J. and Yanget, Y-L. 2001. Morphology and Gas Permselectivity of Blend Membranes of Polyvinylpyridine with Ethylcellulose. Polymer. 42: 6859-6869.

[5] Shao, L., J. Samseth, and M.-B. Hägg. 2009. Crosslinking and Stabilization of Nanoparticle Filled PMP Nanocomposite Membranes for Gas Separations. Journal of Membrane Science. 326: 285-292.

[6] Nistor, C. 2008. Composite Membranes with Cross-linked Matrimid Selective Layer for Gas Separation. Environmental Engineering and Management. 7: 653-659.

[7] Hosseini, S. S., N. Peng, and T. S. Chung. 2010. Gas Separation Membranes Developed through Integration of Polymer Blending and Dual-layer Hollow Fiber Spinning Process for Hydrogen and Natural Gas Enrichments. Journal of Membrane Science. 349: 156-166.

[8] Syrtsova, D. A., Kharitonov, A. P., Teplyakov, V. V. and Koopset, G.-H. 2004. Improving Gas Separation Properties of Polymeric Membranes based on Glassy Polymers by Gas Phase Fluorination. Desalination. 163: 273-279.

[9] Chung, T.-S., Jiang, L. Y., Li, Y. and Kulprathipanjaet, S. 2007. Mixed Matrix Membranes (MMMs) Comprising Organic Polymers with Dispersed Inorganic Fillers for Gas Separation. Progress in Polymer Science. 32: 483-507.

[10] Süer, M. G., N. Baç, and L. Yilmaz. 1994. Gas Permeation Characteristics of Polymerzeolite Mixed Matrix Membranes. Journal of Membrane Science. 91:77-86.

[11] Mahajan, R., Burns, R., Schaeffer, M. and Koros, W. J. 2002. Challenges in Forming Successful Mixed Matrix Membranes with Rigid Polymeric Materials. Journal of Applied Polymer Science. 86: 881-890.

[12] Jiang, L.Y., T.-S. Chung, and R. Rajagopalan. 
2007. Matrimid®/MgO Mixed Matrix Membranes for Pervaporation. AIChE Journal. 53: 1745-1757.

[13] Tantekin-Ersolmaz, S. B., Atalay-Oral, Ç., Tatlýer, M., Erdem-Denatalar, A., Schoeman, B. and Sterte, J. 2000. Effect of Zeolite Particle Size on the Performance of Polymer-zeolite Mixed Matrix Nembranes. Journal of Membrane Science. 175: 285288.

[14] Vankelecom, I.F.J., et al. 1995. Incorporation of Zeolites in Polyimide Membranes. The Journal of Physical Chemistry. 99; 13187-13192.

[15] Bhardwaj, V. 2003. Polysulfone Hollow Fiber Gas Separation Membranes Filled with Submicron Particles. New York Academy of Sciences. 984: 318-328.

[16] Vu, D. Q., W. J. Koros, and S. J. Miller. 2003. Mixed Matrix Membranes using Carbon Molecular Sieves: I. Preparation and Experimental Results. Journal of Membrane Science. 211: 311-334.
[17] Golemme, G., Bruno, A., Manes, R. and Muoioal. D. 2006. Preparation and Properties of Superglassy Polymers Zeolite Mixed Matrix Membranes. Desalination. 200: 440-442.

[18] Moore, T. T. and W. J. Koros. 205. Non-ideal Effects in Organic-inorganic Materials for Gas Separation Membranes. Journal of Molecular Structure. 739: 87-98

[19] Zhang, Y., Ballzus Jr K. J., Musselman, I. H. and Ferrariset, J. P. 2008. Mixed-matrix Membranes Composed of Matrimidß and Mesoporous ZSM-5 Nanoparticles. Journal of Membrane Science. 325: 28-39.

[20] Li, Y., Chung, T-S., Cao, C. and Kulprathipanjaet, S. 2005. The Effects of Polymer Chain Rigidification, Zeolite Pore Size and Pore Blockage on Polyethersulfone (PES)-zeolite A Mixed Matrix Membranes. Joumal of Membrane Science. 260 : 45-55.

[21] Tofighy, M. A. and T. Mohammadi. 2010. Salty Water Desalination using Carbon Nanotube Sheets. 182-186. 